\title{
Procesos identitarios, “campos familiares" y nomadismo: la vida indígena en las fronteras de la modernidad/gubernamentalidad
}

\author{
Leticia Katzer \\ CONICET-INCIHUSA- Centro Científico Tecnológico Mendoza- Argentina. Email: \\ lkatzer@mendoza-conicet.gob.ar
}

\begin{abstract}
Resumen: En los años 1998 y 1999, un conjunto de familias reconocidas como Huarpes, residentes en el departamento de Lavalle, de la provincia de Mendoza, han sido inscriptas como “comunidades indígenas” en el Instituto Nacional de Asuntos Indígenas. Dichas familias vienen protagonizando un momento de reorganización social vinculado fundamentalmente a una constante lucha en defensa de su territorio. El siguiente artículo se propone analizar los dispositivos y mecanismos sociales a través de los cuales los adscriptos étnicos construyen territorialidad y estructuran sus formas de sociabilidad sobre la base del parentesco, del liderazgo familiar y el nomadismo.
\end{abstract}

Palabras clave: identitad, población indígena, campo, nomadismo.

\section{Identity processes, “family fields" and nomadism: the indigenous life in the borders of modernity/governmentality}

\begin{abstract}
In 1998 and 1999, a set of families recognized as Huarpes, residents in the department of Lavalle in the province of Mendoza, have been inscribed as "indigenous communities" in the National Institute of Indigenous Subjects. These families have been starring a social reorganization process fundamentally linked to a constant fight defending their territory. The following article aims to analyze the devices and social mechanisms through which the ascribed ethnic people construct territoriality and structure their sociability on the basis of kinship, family leadership and nomadism
\end{abstract}

Key words: identity, indigenous population, field, nomadism.

\section{Processos identitários, “campos familiares” e nomadismo: a vida indígena nas fronteiras da governamentalidade/moderno}

Resumo: Nos anos de 1998 e 1999, um número de famílias reconhecidas como Huarpes, residentes no departamento de Lavalle, província de Mendoza, foram registrados como "indígena” no Instituto Nacional de Assuntos Indígenas. Essas famílias estão estrelando em um momento de reorganização social ligada 
principalmente a uma luta constante para defender sua territorio. El Este artigo tem como objetivo analisar os dispositivos e mecanismos sociais através das quais os atributos étnicos construiem a territorialidade e estruturam sua sociabilidade em base de parentesco, a liderança da família e do nomadismo.

Palavras-chave: Identidade, población indígena, campo, nomadismo.

$* * *$

\section{Introducción}

El siguiente artículo expone resultados de investigaciones etnográficas llevadas a cabo desde el año 2004 hasta la actualidad, a partir de la relación establecida con un conjunto de familias adscriptas como Huarpes residentes en el secano del departamento de Lavalle de la provincia de Mendoza. Desde el incio del registro etnográfico, se instaló como problemática la tensión respecto a las formas de identificación social y a sus formas de institucionalización a raíz del nucleamiento de adscriptos en “comunidades indígenas", generándose diferencias sobre institucionalizarse como "cooperativas" o definirse como "conjunto de familias" Sin embargo, más allá de estas diferencias, existe cierta unanimidad en autoidentificarse en razón de su territorio y su memoria familiar/genealógica, fundándose así una identificación colectiva basada en lel territori y en el parentesco en el marco de un esquema nómade de vida.

Es decir, adscriptos organizados formalmente en comunidades como adscriptos que no se hallan organizados formalmente, todos ellos se identifican territorialmente sobre la base de la noción de ocupación histórica por sus antepasados. Aún los miembros de las comunidades, que han tenido y tienen "puesto" en los campos, sostienen empíricamente la noción de territorio familiar sobre la base de los lazos de parentesco y recuperan del marco jurídico el fundamento de la "ocupación inmemorial de los antepasados”.

Lo que define al pueblo es el paisaje familiar, definiéndose los nativos como "conjunto de familias", Sobre esta definición se refieren a los “campos familiares", lo que a su vez se conciben como permeables y compartidos por todos. La unanimidad respecto a reconocer la figura de líder familiar -“los más viejos”- como la máxima autoridad (incluso los mismos presidentes de las comunidades) es indiscutible. Del registro etnográfico, en el que se destacan expresiones como "nosotros somos de aquí, aquí hemos nacido, y nos hemos criado, y han nacido y se han criado mis padres, mis abuelos y mis bisabuelos", ha emergido el interés por abordar la relación territorio-filiación familiar más allá de las distintas formas identificativas indígenas. El siguiente artículo se propone analizar los dispositivos y mecanismos sociales a través de los cuales los adscriptos étnicos construyen territorialidad y estructuran sus formas de sociabilidad sobre la base del parentesco, del liderazgo familiar y el nomadismo. 


\section{Vectores analíticos}

En principio, considero necesario hacer explícita la distinción de las nociones de "territorio" y "frontera" en tanto categorías de sentido común- una determinada matriz espacial-temporal, un particular universo de referencia con operatividad ideológica- y como categorías heurísticas de análisis. En tanto categoría heurística, "Frontera" o "Marco" constituye un horizonte de pensamiento y reflexión por fuera de la axiomática de la pureza y la propiedad (Derrida (2001[1978]; 1996) que permite simultáneamente identificar y deconstruir distintas nociones de fronteras como sus formas de instrumentalización dentro de universos de referencia diferenciados, como ser a) en el sentido jurídico-administrativo, como contornos de la nación; b) como espacio de control, de filtración c) como espacio de tránsito, de circulación de marcos de referencias plurales.

Una segunda precaución metodológica que retomo es, siguiendo el análisis de Derrida (1997 [1996]), Hall (2003 [1996]), Cragnolini (2001), la de hablar más en términos de identificaciones que de identidades. Nunca una identidad está dada o es dada naturalmente, pero sí socialmente construida como "disponible" y "posible" en términos de legitimidad -cada cual se identifica tautológicamente con sus identidades-. Es un proceso desigual e inconcluso de mediación y articulación de lo universal/particular que permite al individuo pertenecer a múltiples "comunidades" (regionales, provinciales, familiares, políticas, religiosas,) a la vez, y simultáneamente no-pertenecer de manera total y absoluta. Se trata entonces de múltiples circuitos identitarios y del tránsito entre varias referencias simbólicas que supone el tránsito dentro de campos posibles de elección y selección, si bien dentro de un marco social preexistente.

Se trata entonces de indagar los procesos de identificación con un doble sesgo. Por un lado, un sesgo institucional, -las identificaciones, aunque selectivas, se producen en los marcos institucionales que materializan modelos de racionalidad, modelos de conducta. Por otro lado, un sesgo no institucional, a- formal, que remite a la diferencia, a lo que no se selecciona, a la desidentificación-desapropiación en relación a los modelos identitarios institucionalizados.

Un tercer vector ha sido construido sobre la base de la relectura de los planteos de Poulantzas (1978), Alliés (1980) y Balibar (2005 [1997]) respecto a las relaciones entre Estado, política, economía y territorio, que enfatizan sobre su mutua correlatividad. La relación de poder y la economía es constituyente -de sujetos, de patrones de normatividad- y las formas sociales más o menos estabilizadas, las normas de conducta, son constituidas. La normatividad se diseña desde la razón económica y es el asociacionismo, en tanto principio de normalización ciudadana, el que constituye los cimientos de la productividad económica. La relación política del poder precede y funda las relaciones económicas de explotación (Clastres, 1974, citado en Poulantzas, 1978). Las matrices -simbólico/ organizacionales- espaciales y temporales, en función de las cuales se 
institucionalizan y constituyen normas de conducta, son expresión y delinean a la vez, modos de producción específicos; sus transformaciones van de la mano de las transformaciones éstos.

Como ya ha sido formulado, existe una asociación dialéctica entre espacio, historia, memoria e identidad (Foucault, 1998 [1979]; Halbwachs, 2004 [1968]), Nora (1984), Pacheco de Oliveira, 1999; Ricoeur, 2008 [2000]; Jelin, 2002, Barabas, 2003). Parto de la premisa analítica de que las condiciones de producción de la existencia de las familias adscriptas como Huarpes son ordenadas de acuerdo a una serie de principios activados por las prácticas sociales y que se expresan simbólicamente en marcas/ huellas que se imprimen en el espacio, territorializándolo. De esta manera, la categoría territorio cultural o etnoterritorio (Barabas, 2003) ayuda a precisar el análisis en este sentido. El etnoterritorio, definido como el "territorio histórico e identitario en el que se inscriben las prácticas y símbolos culturales de cada grupo a través del tiempo" (Barabas, 2003:48), remite al origen y a la filiación del grupo en el lugar y constituye el soporte de la producción y reproducción de la existencia de un grupo étnico a lo largo de la historia.

Me refiero con territorio étnico no sólo al espacio geográfico del secano, sino más a un "lugar de memoria”, en términos de Nora (1984) como un espacio tangible e intangible donde se producen y se recrean sentidos. Los actores materializan las memorias a través de diferentes marcas que se inscriben en el espacio (Jelin, 2002), Barabas (2003) y que pueden ser materiales o inmateriales, naturales o artificiales. Pienso en las inscripciones simbólicas y materiales de modos de producción histórica y procesos globales, como las marcas de la modernización del espacio provincial y de la gubernamentalización estatal, por un lado, y en las reelaboraciones singulares y su acomodamiento por parte de los indígenas a sus singulares modos de producción territorial y marcos colectivos de memoria $^{2}$. El espacio, reservorio de recuerdos, es el soporte de la identidad y por ende de la memoria.

\section{Contextualización etnográfica}

El registro etnográfico remite centralmente al área de las Lagunas, hoy secano de Lavalle, puesto que, correlativo a la colonización de valles centrales -donde también se han nucleado históricamente los Huarpes- éstos fueron gradualmente arrinconados en el áerea carente de interés productivo; también dado que se trata del territorio históricamente cedido a los indígenas y actualmente reclamado por ellos y en litigio; y por último, la continuidad en la ocupación del lugar imprime, en términos identitarios/ políticos, características singulares.

Actualmente, constituye gran parte de la "zona no irrigada" de la provincia, aquella que carece de sistema de riego artificial, que no se destina a explotaciones agrarias intensivas y que se consigna preferentemente para la actividad pecuaria extensiva; actividad que se inicia a partir de la reduc- 
ción de los indígenas. Hasta hace unas décadas atrás el modo de producción de autosubsistencia estaba basado en la pesca, la caza y el cultivo (maíz, zapallo, trigo) a través del aprovechamiento del desborde los ríos en épocas de crecida. Sin embargo, resultado del modelo de producción económica y las implementaciones tecnológicas instaladas primero por conquistadores, luego por elites dominantes, condujeron a un drástico desecamiento de la zona, por el que el cultivo y pesca debió ser abandonado y por el que existe una sobrecarga de animales. Producto del desarrollo de la agricultura intensiva en el oasis, del endicamiento de aguas de los ríos Mendoza y San Juan en sus cursos superiores a los fines de regadío, del desmonte masivo de algarrobos que se efectuó a los fines de construcción del ferrocarril y obtención de leña y de las especulaciones financieras respecto al régimen de propiedad, esta zona sufrió un progresivo avasallamiento territorial y despojo hidráulico.

El secano contiene cuatro distritos: Lagunas del Rosario, San José, Asunción y San Miguel. Tal como lo ilustra la figura (6), la población general se halla heterogéneamente dispersa, es decir en los puestos, que constituyen unidades productivas y residenciales de familias nucleares con una distancia promedio entre de $10 \mathrm{Km}$. aproximadamente entre sí, unas 3 horas a pie si las condiciones climáticas y los accidentes del terreno lo permiten (guadales, medanos, montes, etc.)-. Eexisten además pequeños poblados/parajes- caseríos de no más de 30 viviendas- entre los que se destacan Lagunas del Rosario, Asunción, San José y San Miguel-. Estos núcleos residenciales colectivos se fueron construyendo y consolidando, según mis interlocutores, de la mano de la edificación de las escuelas en tales emplazamientos y funcionan como centros cívico-ceremoniales, es decir, como santuarios, en la medida que presentan cada uno, escuela, centro de salud y/ o posta sanitaria, capilla y cementerio.

La economía es una economía fundamentalmente de subsistencia. La principal fuente de recursos lo constituye la ganadería caprina. Las unidades productivas son los puestos, que a excepción de aquellos pertenecientes a familias residentes en los poblados, constituyen simultáneamente, como se señaló anteriormente, unidades residenciales de familias nucleares. A este recurso ganadero se agregan la extracción de algarrobo para leña y confección de mobiliarios tales como sillas y mesas; la recolección de algarroba y chañar durante el mes de febrero, para la elaboración de patay y aloja y la recolección de junquillo en el mes de junio, para la confección de canastos y para la venta a los fabricantes de escoba.

Quienes fundamentalmente atienden animales y realizan actividades de caza son los hombres, muchos de los cuales son artesanos de cuero, y en ocasiones, canasteros. Si bien las mujeres se encargan también de atender a los animales como las aves del corral, de la recolección de algarroba y leña, de cortar junquillo y de la cestería, las actividades identificadas como exclusivas de ellas, son las actividades artesanales vinculadas al tejido, tal como lo expresa (NL, tejendera de El Puerto): “acá muchas mujeres son "tejenderas". El tejido se realiza en telar y bastidor, y son utilizados tintes naturales como la jarilla, el jume, el pájaro bobo y la espina blanca. 
Tanto tejidos como canastos y productos en cuero, además de ser recursos de uso local, son vendidos por encargo a turistas e individuos no residentes que se acercan al lugar, y en el Mercado Artesanal de Mendoza-ubicado en el subsuelo de la Secretaría de Turismo de la Ciudad de Mendoza- por parte de aquellos artesanos que pueden trasladarse a dicha ciudad.

La venta de chivos se concentra a partir de abril y en el último trimestre del año, y la extracción de estiércol caprino para la fertilización de cultivos y de arena se realiza en invierno. En esta última actividad, algunos varones jóvenes venden su fuerza de trabajo por jornada -que ellos denominan "palear"-, depositando ambos recursos en camionetas provenientes del área urbana, que ingresan al lugar una o dos veces por semana, y que en el caso de los “areneros" -tal como los denominan los nativos- pertenecen a empresas constructoras.. El estiércol y la arena también son usados para la elaboración de adobe, actividad que he registrado en Asunción, para uso propio y venta, local y no local, siendo transportado también en camionetas provenientes del área irrigada y urbana, que ingresan al lugar.

Otro recurso económico es la venta de fuerza de trabajo para la cosecha de la vid en la zona de oasis de Lavalle, fundamentalmente en California y Gustavo André, áreas a las que individuos y/o familias -los "cosechadores"- se trasladan de manera agrupada y semanalmente en camionetas, regresando en el fin de semana, permitiéndoles mejorar su economía al aumentar sus ingresos. Se trata de individuos y/o familias que residen fundamentalmente en Asunción, o en puestos cercanos a la ruta.

Por ultimo, también en los parajes de fácil accesibilidad, cercanos a la ruta nº142 como Asunción y la Reserva Telteca.

Es decir que el dinero se obtiene de la venta de chivos, artesanías en cuero, tejidos, canastería, adobe, estiércol; de la venta de fuerza de trabajo en la extracción de arena y estiércol y en la cosecha en la zona de agricultura intensiva; como así también de la actividad turística. Las familias que sólo mantienen una economía de subsistencia -que son la mayoría-, sin acceso a dinero, obtienen los productos alimenticios manufacturados por medio del trueque, intercambiándolos por tejidos, productos en cuero, panes, animales, huevos. Sin embargo, quienes tienen mayor acceso a la comercialización y obtención de dinero son aquellas familias residentes en las cercanías de la ruta (ruta nacional $n^{\circ} 142$ ) y poblados, para quienes resulta más accesible, en términos viales, el contacto con no locales, turistas o no, para la comercialización de productos.

\section{De territorialidades e "identidades" en la política instrumental/productivista}

La identidad es producida por el poder/gobierno, entendiendo que éste es una estructura total de acciones dispuestas para producir posibles 
acciones, incitando/facilitando ciertas formas de acción, y dificultando/ inhibiendo absolutamente otras; sin embargo es siempre una forma de actuar sobre la acción del sujeto ; designa modos de acción calculados destinados a dirigir la conducta de los individuos o de los grupos, a actuar sobre las posibilidades de acción de los otros, estructurando el campo posible de acción de los otros (Foucault, [1982] 2002, 2001). Se trata del "gobierno de la individualización", de una una forma de poder que hace sujetos individuales. El Estado nacional realiza la unidad de los individuos del pueblonación dentro del mismo movimiento por el cual él forja su individualización. Él instituye, a través de la unidad territorial, la homogeneización política-pública (Poulantzas, 1978).

La trama que estructura política y públicamente a la población, se encuentra guiada por la razón económica. El estado moderno, regula, mide, calcula, controla en función de la norma, el espacio y la temporalidad, unificando toda su diversidad, uniformizando las diversas temporalidades y los diversos espacios (Ibid). Así, en el marco del régimen gubernamental hay una asociación directa y de implicancia mutua entre identidad, territorio y productividad: La demarcación de fronteras sociales (cartografías) es, siguiendo a Alliés (1980) un proceso político tendiente a la acumulación de capital, por lo cual la función de la administración es la de garantizar la maximización de la productividad.

En primer lugar la unidad identitaria pretende ser garantizada desde la estrategia territorial: el territorio es instrumentalizado políticamente como núcleo y reflejo de cohesión social, como un medio de dominación política. Se trata de la instrumentalización política del espacio, de su "uso" político y social, siendo entendido como medio de asegurar la dominación política, de domesticar las interacciones sociales y su movimiento espacial, y de crear una unidad. La frontera, en este sentido, es una institución producida por el estado liberal y sometida a sus necesidades. Ella contiene el territorio, toma su valor dentro del funcionamiento del Estado en tanto que factor de cohesión social.

En este modelo gubernamental ligado al modelo de acumulación de capital hay una asociación directa entre la producción del territorio y la administración. A partir de un modelo tecnicista de organización, aquélla tiene por objeto reproducir el territorio y asegurar la cohesión en el modo de producción capitalista. La administración es entonces una instancia constitutiva del territorio, por cuanto el espacio se convierte en un objeto racionalizable, tratado como un todo homogéneo.

En segundo lugar, el espacio se convierte en un objeto racionalizable, tratado como un todo homogéneo cuando se ve en él una rentabilidad posible (Alliés, 1980). El territorio no tiene valor político independiente de su valor económico, agrícola. Así, el Territorio moderno es aquel espacio constituido como objeto de dominio; instrumentalizado política y económicamente. 
Entre los procesos históricos globales vinculados a la modernización del territorio provincial se encuentran aquellos procesos económicos vinculados a la producción de la agricultura intensiva y desarrollo del oasis; los procesos jurídico-políticos, es decir, los actos por los cuales se efectivizan las subdivisiones jurisdiccionales para el control y regulación de las formas de sociabilidad, trabajo y residencia; ligados a éstos, los procesos catastrales; y la configuración de las formaciones discursivas -normativas, científicas e ideológicas- que legitiman tales modos de estructuración y ordenamiento social (Katzer, 2009, 2012).

Así, la asociación simbólica entre la idea de sembrado de campos y plantación del verde público con la idea civilizadora enhebrada al interior de la semiósfera instrumental modernista constituyó el fundamento de la dicotomización asimétrica del espacio provincial en los polos Oasis y Secano. La semiósfera moderna objetiva el espacio, lo traduce a objeto de dominio, como unidad de explotación. Producto de la producción económica agrovitivinícola intensiva en el oasis, del endicamiento de aguas de los ríos en sus cursos superiores a los fines de regadío y de construcción de diques con fines turísticos, del desmonte masivo que se efectuó a los fines de construcción del ferrocarril y obtención de leña, la zona del secano ha sufrido un acentuado un acentuado proceso de aridización y de desecamiento de las lagunas, y consecuentemente de despojo hidráulico. Es decir, se ha instituido una distribución desigual del agua, al punto que, salvo en coyunturas específicas, el aporte de agua de los ríos es prácticamente nulo, lo cual se traduce en una radical disminución de aguadas y pasturas. El aprovisionamiento del agua en el secano se da mediante el sistema pozobalde. Los terrenos para el pastoreo son bien limitados y se reducen a áreas de inundación y márgenes de los ríos. Es decir que la subsistencia queda enteramente determinada por los niveles de precipitaciones y las proporciones de nieve en la cordillera, dado que los aportes de agua de los ríos de Mendoza provienen del deshielo de ésta. Resulta ilustrativo el relato que presento a continuación:

"Mi abuela me sabía contar, acá en San José eran trigales todo esto ... claro es lo que pasa, antes no había tantas fincas como ahora, entonces el agua del río pasaba por acá ... yo me acuerdo ... hasta esos años que yo sé que habrá sido en el 45' todavía habían partes en que se sembraba maíz, zapallo y se guardaba para el invierno ... acá mi abuela...el zapallo, mi abuela lo cortaba y lo colgaba en los algarrobos y lo guardaban para después comerlo..lo que ahora no hay nada ... mi abuela carneaban una vaca, un ternero ... y a lo mejor una pierna de carne la hacía charqui-con sal-, y después lo embolsaban y lo guardaban ... y sabían esperar el invierno ... en el invierno lloviznaba, lo que yo le digo ... hasta el clima ha cambiado.. antes sabía haber días, semanas que llovía día y noche, cuando yo era niño, y yo me acuerdo ella sabía agarrar majar el charqui en el mortero, lo machacaba bien y con eso hacía el [el locro?] con maíz....antes había tanto algarrobo en la medanada, el agua venía ... y pasaba por los yauyines, la laguna grande, y en El salto se juntaba el río, alguna 
algarroba queda, pero no se crían como antes, tan grande, tan linda, por la sequía.. este verano tendría que se jardín los campos (LF, adscripto Huarpe adulto, Asunción)

La dupla política, económica y simbólica Oasis-Secano es la que vertebra el ordenamiento espacial y la reestructuración político-administrativa. En el oasis, locus de expansión de los frentes económicos agrovitivinícolas y de mayor concentración poblacional, el aparato administrativo se ve ampliamente multiplicado. De lo contrario, en el Secano, donde aquellos frentes no actúan directamente, la concentración poblacional merma significativamente, como por ende también, la presencia del aparato administrativo y el control político. En esta diferencia se origina la precipitación de los conflictos catastrales e irregularidades en el registro de propiedades en el área reconocida como territorio indígena a lo largo de todo el siglo XIX, generándose en la actualidad, grandes y cada vez más complejas, disputas territoriales en esta zona (Katzer, 2009, 2012).

La sedimentación local de las propiedades y evoluciones ecológicas y políticas en el lugar ha incidido en la morfología social en la población indígena allí residente, teniendo que crear respuestas adaptativas y definir estrategias de supervivencia específicas, manteniendo una continuidad y recreando sentidos de pertenencia a través de la producción de una memoria colectiva.

\section{Campos y liderazgo familiar en las fronteras de la gubernamentalidad}

Los procedimientos de gubernamentalización provincial han repercutido en el actual modo de existencia indígena pero no se impusieron unilateralmente (Katzer, 2009). Mas bien acomodaron sus formas organizativas, sus ideas y creencias a las impuestas, en diversos grados de ajuste cultural tanto de tipo externo como interno, institucionalizando formas de sociabilidad, trabajo y residencia en función de actualizar el modo de vida nómade y comunitario, y de garantizar la cohesión social mediante el vínculo que establecen con la tierra, con la producción ganadera y los liderazgos familiares. El resultado ha sido la recreación del modelo de dominio de recursos, instituyendo la pauta de "marcar" y "señar" a los animales, y en pocos casos, la inscripción de campos en el registro de la propiedad. A la forma de trabajo central ganadera y recolectora, se han incorporado formas de trabajo a la red de mercado, como es la venta de recursos naturales -junquillo y estiércol-, la venta de chivos, la comercialización de productos artesanales, tales como tejidos, canastos, productos en cuero, y la producción turística (Ibid, 2012).

La actualización activa de un modo de vida económico-social localmente singular es, siguiendo a Anton Burgos (2000), un criterio que se mantiene en las áreas en las que se practica el nomadismo ganadero, dado 
en que son áreas en las que no es posible otra actividad económica y porque posibilitan el resguardo de saberes históricos vivos. Entre las formas de sociabilidad ligadas a estas nociones asociadas a la movilidad se encuentran el desplazamiento residencial familiar (traslado de puestos); las “campeadas”, que constituyen desplazamientos esporádicos por parte de la población adulta masculina asociada a su vez a los requerimientos de la actividad del campo, el cuidado de los animales y la caza; "salir a cortar el rastro”, que constituye una práctica que delimita simbólicamente el espacio de movilidad social, creando un ámbito de identificación, interacción y comunicación social a través de las huellas ${ }^{3}$, y la rutina ritual-religiosa anual, que también implica desplazamiento residencial temporario, puesto que las familias se trasladan a la vivienda temporaria (la "ramada”) durante el tiempo que transcurre el ritual (tres días).

Con todo, es de notar la generalizada exclusión identificativa sobre el modo residencial sedentario y el cercado de 'propiedades':

“En estos campos, no existen alambrados divisorios, "los límites los marcan los animales (...) se comparten pasturas y aguadas (...) sino, no puede vivir uno, que cada uno tenga un pedazo de tierra y que diga, no, esto es mío, acá no se puede, usted larga los animales y van de aquí a 8 o 9 kilómetros para comer, a campo abierto, como uno dice, campo libre (...) y siempre hay un respeto", "hay que ocupar el campo...acá es tierra comunitaria, sin alambrado, es campo libre ... siempre ha sido así, nosotros decidimos quien puede ocupar el campo” (RA, hombre Huarpe adulto. El Puerto. Febrero 2007).

La unidad residencial y productiva institucionalizada es la del “puesto”, "rancho” elaborado con material autóctono, con un pozo-balde, un corral y su respectiva ramada. La ramada es el espacio que más se usa la mayor parte del año, dado los intensos calores; es el espacio de reunión social, de encuentro entre parientes y vecinos al atardecer, cuando son narrados los sucesos ocurridos el día, lo "rastreado". Durante el verano, la familia pasa allí todo el día, inclusive la noche. El desplazamiento residencial familiar opera como núcleo constitutivo de la organización social endógena. La movilidad de los emplazamientos de aguadas y pasturas, y por ende de los animales estructura la movilidad de los puestos:

“Las cabras van a tomar agua al pie de los médanos. Las aguadas o jagüeles son bajadas que se hacen hasta que llega a la primer napa de agua a unos siete u ocho metros de profundidad...antes a las aguadas las hacían con pala y con un rastrón tirado por animales... donde hay río, los animales toman de ahí y hacen aguada al lado del río” (EF, adscripto Huarpe adulto. Asunción, 2009).

La movilidad de puestos ha sido también identificada por funcionarios por mí entrevistados de la Dirección de Ordenamiento ambiental en el Registro Único de Puesteros (RUP), aludiendo a que "cambian los puestos, cambian los nombres, una vez está en un lugar, otra vez en otro, se llama de 
otra forma”. Así, el puesto es una unidad elástica e inestable, cuyas características de confección posibilitan su traslado, resultando ser una de las respuestas culturales que tradujo al sedentarismo las formas históricas de nomadismo.

Es posible observar un patrón de nucleamiento ${ }^{4}$ característico cuyos ejes de diseño están dados por los lazos de parentesco, que son los que determinan la organización y distribución espacial de las viviendas: “en las familias cuando vos sos chico te van regalando animales y los puestos se hacen cerca de la casa del padre” (FG, Lagunas del Rosario, octubre 2008). El patrón de configuración de campos y de nucleamiento residencial representa la estructura de parentesco familiar.

Dada la movilidad y dispersión de los animales en los campos, la práctica vehiculizada para la reunión de los animales y seña y marca de su cría es lo que se denomina la campeada/piolada/recogida de animales. Asimismo este es el momento en que se realiza desde hace unos años, la vacunación pertinente. Constitutiva de la dinámica económica local esta “junta de animales”, “campeada” o “piolada”, se realiza en el mes de abril. Es una actividad colectiva y masculina, a través de la cual se junta el ganado para ser marcado y señado y para efectuar la vacunación. La "piolada” consiste en enlazar las dos patas traseras o delanteras para marcar al animal. Enlazan así al animal mientras están corriendo para detenerlo y tirarlo al piso. Es una práctica colectiva que nuclea a la población masculina. Cuando se determina la fecha para hacer la recogida de animales, la juntada se hace entre todos. Pueden durar de tres hasta dos semanas, periodo de tiempo en el que los hombres se ausentan de los hogares:

"Las pioladas o recogidas de animales se organizan entre las familias, cada familia tiene un lugar. De cabras y ovejas hay dos recogidas al año, se van a juntar cabras y ovejas que se van y no vuelven y las juntan a todos en un lugar común, entre varios puesteros. Esto puede tardar una semana, y una vez que están los animales encerrados, los separan, algunos están marcados, los que no están marcados se van con las cabras que están marcadas” (MA, adscripto Huarpe adulto, Las Heras).

No se registra ni la noción de herencia ni la de "transferencia de tierras” en los términos en que se describen en la legislación (ley provincial n 6920- 2001/ 2009); el campo se ocupa sencillamente. Las categorías de "herencia”, "transferencia” son utilizadas en conexión con la reapropiación de la categoría de “comunidad” sólo situacionalmente, en contextos de formulación de demandas al Estado. Sólo desde ese léxico pueden "presentarse” puntos de vista. Por lo contrario, los adscriptos Huarpes de procedencia mendocina defienden con firmeza la noción de “ocupación del campo”. Interpreto que, en gran parte, esta concepción se fundamenta en el hecho histórico particular de Mendoza de que son campos que los residentes indígenas han heredado por ocupación y cargo familiar, primero por merced, un territorio que se otorga y se deja a cargo de un cacique; luego por entre- 
ga del Estado provincial, “para que lo trabajen y no se hallen inactivos” (tal como consta en el ddecreto de 1838; y luego por títulos supletorios que se basan para su otorgamiento, en la ocupación histórica generacional -en el sentido de residir y trabajar la tierra--, cuyo otorgamiento se vio favorecido por el plan de regularización de la tenencia de tierras, primero a principios de siglo XX y luego con la ley provincial 6086/96 de arraigo de puesteros. Y por otra parte, basándome en mi propio registro etnográfico en Mendoza, entiendo que se refiere a la idea de que en el campo se habita y se trabaja, se desempeñan actividades, funciones, cargos, se lo recorre, se lo conoce, se dejan huellas. La gente se ocupa del campo, con dedicación, compromiso y amor. Mis interlocutores no se refieren a que los campos se heredan, sino a que se los ocupa, campos como espacios donde la gente nace, se cría, vive, transita, y muere; las distintas generaciones van ocupando el espacio del monte según lazos de parentesco, y en los contornos de éstos. Por último, remite también a la noción de ocupación familiar del campo, fundada en la idea de ocupación histórica de los campos por los antepasados, por los antiguos cacicazgos.

La organización territorial en campos es estructurada en la forma del liderazgo familiar, reconocido como la forma universal de autoridad legítima ${ }^{5}$. "Líder familiar" ha sido definido por mis interlocutores como “ el más viejo, quien conoce mejor sobre los animales, y el que se ha hecho más cargo del campo, el que ha demostrado más destreza para cuidar a los animales, el que ha cuidado de la gente, que carnea y comparte” y los atributos de autoridad refieren a que "frente a una necesidad, él se hace cargo, lo llaman a él, organiza la piolada, es una autoridad en el trabajo, comanda la cercanía, es al que hay que pedirle permiso para hacerte un puesto”. De acuerdo a mi registro etnográfico, se le atribuye tres grandes propiedades: direcciona las campeadas, tiene atributos de decisión en ellas, las cuales son realizadas en su puesto; es referente por la inteligencia que se le atribuye para llevar adelante la vida en el campo; y es fuente de memoria, conocimiento que acumulan y transmiten sobre la historia del lugar. El conjunto de estos atributos le imprimen a su vez la autoridad para direccionar conflictos entre individuos. Es decir que el líder familar, resume y condensa los "marcos colectivos de la memoria”. Aquellos adultos que por su capital mnémico y su capacitad narrativa de transmitir historia vivida como conocimiento respecto las actividades económicas centrales, ganan el prestigio y respeto que los convierten en líderes familiares.

Como es de notarse, en el marco cultural indígena, el espacio no es objetivado, traducido a objeto de dominio. A diferencia del oasis, el terreno del secano no se halla parcelado en propiedades ni presenta alambrados divisorios. La ocupación de campos responde a un patrón estructurado en torno a la familia extensa, y las fronteras sociales entre familias son lo suficientemente elásticas de manera tal que aguadas y pasturas, componentes vitales para la reproducción de la existencia local, basada principalmente en la ganadería caprina nómade, son compartidos por la totalidad de las familias. Así lo refería uno de mis interlocutores: "yo vivo acá, yo soy 
de acá, y esto no es mío, yo le pertenezco a esto, a estas tierras, y esas son la diferencias, que son las que nos ofrecieron los europeos...nosotros

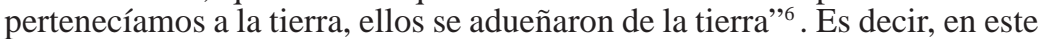
modelo territorial la asociasión y el medio se asumen como un todo en una relación a-instrumental, de entre-hospedaje y con expectativas comunes de bienestar. La “cesión” de tierras se da por la sencilla ocupación histórica y la memoria genealógica: "Cuando un pariente quiere hacerse el puesto, se le ayuda, se les da algunos animales para que empiece de a poquito”, “por eso, "el campo no se vende, se ocupa"7 . Interpreto que esta noción de ocupación se desprende de la semiósfera indígena que no traduce a la naturaleza como objeto de dominio y apropiación; considero que confirma la noción de desapropiación, la idea de que ocupar el campo implica sentirse "huéspedes en la tierra”, huéspedes permanentes en el monte y no propietarios de él. Esta idea de “ocupación” se aleja bastante de la categoría de “ocupas”, en el sentido que se le da occidentalmente, alguien que ocupa ilegítimamente un territorio que no es propio y es propiedad de otro. Más bien, confirma la metáfora del caminante nómade.

Así, el potencial heurístico de la categoría de “nomadismo” para dar cuenta de prácticas y formas de sociabilidad registradas en el ámbito de la producción de la vida de adscriptos étnicos huarpes es innegable. Me refiero con tal término a un esquema cultural, a una actitud y modo de pensamiento tal como ha sido tratado por la filosofía derridiana. Esta filosofía lo define como una forma de pensamiento no moderna, según la cual el espacio no se halla objetivado sino que es de tránsito, inapropiable, como pasajes que conducen siempre a otra parte (Cragnolini, 2000). Son los "viajeros” que desconocen el calor del hogar -tal como lo ha definido la modernidad, como "lo más propio"- porque su lugar se halla siempre en otro lugar, un lugar no terrenal, y por ello siempre "huéspedes” en la tierra libre. Es a la idea de movimiento y a su tradición nomádica que ligan sus actividades económicas, y no la inversa. Es un componente fundamental en la construcción y regeneración de su identidad como también la principal fuente de resistencia frente a la intención del "Estado-nacional” de "integrarlos", de hacerlos “pertenecientes” de manera fija y sedentaria. Implica y articula adaptación al medio ecológico, la creación activa de una economía local y un modo de vida particular.

Es decir que las formas de organización social institucionalizadas constituyen respuestas culturales adaptativas y estratégicas que configuran, desde una semiósfera nómade, un ordenamiento organizativo estructurado por el parentesco, disperso e inestable, traduciendo al sedentarismo a modo de "discurso oculto", las formas históricas de sociabilidad, trabajo y residencia, ligadas al traslado residencial y al liderazgo familiar. Tal ordenamiento se sostiene, perpetúa y recrea sobre la base de la construcción de una memoria colectiva. Son formas de vida y acción elaboradas y mantenidas por los indígenas que no se identifican con las posiciones subjetivas legítimas de dentro de la formación discursiva gubernamental y que por tanto se inscriben como discurso oculto. 


\section{Memoria familiar/genealógica como matriz de construcción del territorio étnico}

"Si señora, nacido y criado aquí...soy indio, huarpe, lagunero, mis padres, mis abuelos han nacido y se han criado aquí" (TG, adscripto Huarpe adulto, Lagunas del Rosario, marzo 2008).

“(...) me quisieron sacar... 'mándese a cambiar, yo he nacido y me he criado aquí' (LF, adscripto Huarpe mayor, Asunción, abril 2010)

"Somos nativos, nacidos y criados aquí, y me siento orgulloso..mi abuela era india, india, india, Paula Guaquinchay se llamaba, y la madre de ella se llamaba Eulogia Guaquinchay... mi abuelo era el único que parece ya descendía de otro, porque él era Fernandez" “yo empecé a fumar a los 21 años y le pedía permiso a mi abuela..uuu... mi abuela sabe que...ella con la chalita del choclo y la sabía guardar y con eso sabía armar los cigarros...ella era hija del cacique...el cacique ha sido se ve el fundador...esos viejos han sido todos caciques, tenían carros, mulares, han tenido muchos animales, eran los dueños de los campos” (LF, adscripto Huarpe mayor, Asunción, abril 2010).

La construcción de la identidad sociativa aparece anclada territorialmente: el lugar donde emergieron sus antepasados, el lugar donde sus antepasados han nacido y se han criado. El hecho de nacer y criarse en el lugar aparece señalado en los relatos como una marca de singularidad, una marca identificatoria como así también como capital simbólico colectivo. La memoria colectiva, genealógica y familiar es la que crea, fundamenta y legitima la organización comunal de los campos. Es mediante la intervención de la memoria que adquiere valor y que se garantiza su aplicación es decir, es la memoria colectiva, genealógica y familiar, la que interviene para que la ocupación del campo sea legítima. Es decir, existe una conexión necesaria entre territorio y parentesco ${ }^{8}$, entendido este como una construcción cultural que ordena la organización social en el espacio (Fortes y Evans-Pritchard, 1975 [1940], Woortman, 1995, Tamagno, 2001, Valle, 2003).

De este modo, en la producción del territorio étnico el uso de la genealogía es indiscutible. La genealogía es el instrumento que utiliza "ego" (o una familia entera) para recrear su memoria genealógica (parentesco memorizado) y familiar (memoria que abarca todo lo vivido por una familia) (Connerton, 1993 [1989]). Como tal es un dispositivo político instrumentalizado para fundamentar y legitimar la transmisión/transferencia de campos y liderazgos -económicos/familiares-, como la prueba de la historicidad de la ocupación del campo:

"Ya mi bisabuelo había hecho una declaración de que poseía este campo en el año mil ochocientos sesenta y pico, vino hasta Lavalle 
e hizo un testamento, entonces se pidió un título supletorio, que lo otorgaron, cuando en realidad se tendría que haber hecho una sucesión...el tema es que en esa época lo reclamábamos como familia Azaguate.. ahora el Ramón Azaguate es el cacique, porque es el más viejo, y es el que siempre se ha hecho cargo del campo, después de mi tío Javier... Mi tío Javier era muy respetado, era cacique, a él se le pedía permiso para todo, para cazar en el campo, hasta para andar en el campo (MA, adscripto Huarpe adulto, El Puerto, 2006)

"En Lagunas, yo he sentido nombrar a los Jofré, González y por ahí Nievas...ellos han tenido campo, esas familias han tenido campo, ellos han sido caciques...Mi abuela Paula Guaquinchay era cacique, porque había sido hija de cacique” (LF, adscripto Huarpe mayor, Asunción, abril 2010)

"El campo Jofré era del padre de mi abuela Jertrudes Jofré, Rosario Jofré, que en realidad era Gallama, se cambió el apellido... Daniel Gonzáles, también Gallama, primo hermano de mi abuelo, era como un líder del campo, toda la gente lo respetaba y cuidaba a la gente. Decía mi abuela que todos los días carneaba un ternero y lo repartía. También Vicente González, hermano de mi abuelo, también líder respetado, él ordenaba las campeadas, este fue el último líder viejo que falleció hace ocho meses... José Molina protegía toda la zona del límite con San Juan, también era Gallama (RD, adscripto Huarpe adulto, Lagunas del Rosario, enero 2010)

Según FC, “, Juan Manuel Villegas, mi bisabuelo murió en 1945, él era "como el dueño del pueblo", y me contaron que tenía varias esposas” (FC, Joven adscripto Huarpe, San José, 2009); según TV había escriturado el campo en el año 1931. Los hermanos TV y PV nacidos y criados en San José, quedaron a cargo de su abuelo Juan Manuel Villegas y a su muerte heredaron el campo que tiene 11.500 has actualmente inscriptas en el Registro de la propiedad. Hoy "Para hacerte puesto en el campo tenés que pedirle permiso al P” (FC, Joven adscripto Huarpe, San José, 2009)

Apoyándome en los relatos de campo y en los árboles genealógicos elaborados con los interlocutores que los expresaron, he identificado tres grandes campos familiares (campos de familias extensas) que delimitan y expresan territorialmente su estructura de parentesco: el campo de la familia Azaguate, el campo de la familia Gonzalez-Jofré y el campo de la familia Villegas-Guaquinchay. Reconociendo que las formas y usos de la memoria genealógica están condicionadas por determinaciones históricas y socioculturales (Connerton, 1993 [1989]), la memoria genealógica es en el caso de las familias adscriptas como Huarpes, un dispositivo que funciona, en tanto soporte de la identidad sociativa y de la identificación de los campos, como soporte de la construcción y defensa del territorio étnico. La genealogía es entonces un dispositivo político que utilizan las familias para alimentar su memoria genealógica y eventualmente, la memoria familiar, al 
ponerse a buscar la huella de sus antepasados. En esta memoria genealógica hallan fundamento sus históricos reclamos territoriales (Katzer, 2009).

\section{Consideraciones finales}

Sin universalizar la "ocupación inmemorial” sobre el espacio como criterio identificatorio, sostengo que la construcción de una conciencia étnica se funda en la identificación sobre aquél -respecto a formas de sociabilidad, trabajo y residencia-, sobre la memoria que en él se inscribe y sobre las dinámicas sociales del recuerdo y de la anamnesis. La filiación cultural y la orientación cultural se tejen sobre la base de estos aspectos. Los avatares de la historia colonial y nacional unida a su propia capacidad de adaptabilidad estratégica ha permitido a los Huarpes conservar buena parte de su territorio histórico. Más allá de las tensiones y diferencias generadas a raíz del nuclemiento de adscriptos Huarpes bajo las formas jurídicas de corporalización pública, existe cierta unanimidad en autoidentificarse en razón de su territorio y su memoria familiar y genealógica generándose así una noción de identidad colectiva basada en la identificación territorial y en el parentesco, unidos por la memoria. Por otra parte, la escasa importancia económica del área de residencia unida al difícil acceso a la misma, han determinado una asistemática presencia institucional que posibilitó el mantenimiento de muchas de las formas políticas históricas ligadas al liderazgo familiar y al nomadismo.

Si bien los grupos étnicos no están basados simple o necesariamente en la ocupación de territorios exclusivos, en el caso de los Huarpes la continuidad histórica y exclusividad de la ocupación territorial, ha actuado como instancia de marcación identificatoria, de estructuración organizativa y de cohesión social, y ha permitido su expresión y ratificación continuas. El modo de producción territorial constituye una marca de indianidad. Lo que construye su modo-de-ser-en-común, es el modo de anudamiento de sus identificaciones sobre el espacio. Al referirse a sus raíces identificativas, los adscriptos Huarpes aluden al territorio en el cual nacieron y se criaron como así también donde nacieron, se criaron y murieron sus padres, abuelos y ancestros.

Los procesos de demarcación de fronteras simbólicas, de producción de identificaciones y de estructuración de formas organizativas, como su continuidad y coherencia en el tiempo, se inscriben territorialmente por medio de la producción de memorias. En conjunto estos relatos sobre el pasado y el presente han construido y continúan construyendo un particular sentido de pertenencia étnico/territorial que otorga a la población indígena local, una continuidad y coherencia identitaria. 


\section{Notas}

${ }^{1}$ Para detalles sobre la descripción de las diferencias en el proceso de inscripción al Registro Nacional de Comunidades Indígenas (RENACI) del Instituto nacional de Asuntos Indígenas (INAI), véase Katzer (2010).

${ }^{2}$ El abordaje de los procesos de gubernamentalziación estatal, sus reconfiguraciones e implicancias en las formas organizativas en contexto provincial ha sido desarrollado en Katzer (2009, 2010, 2012).

${ }^{3} \mathrm{El}$ "rastro" es la huella que toda aquella persona o animal deja en el monte en su paso. Se trata de huellas de pisadas y olores.

${ }^{4}$ Tamagno (2001) ha propuesto el término "nucleamiento" para designar a los conjuntos que se constituyen a través de dinámicas flexibles.

${ }^{5}$ Cabe la aclaración dado que la autoridad de los líderes cluster y presidentes de las "comunidades" no es admitida por la totalidad de las familias e individuos.

${ }^{6}$ Fragmento entrevista a MA, hombre Huarpe adulto. Febrero 2007).

${ }^{7}$ Fragmento entrevista a RA, hombre Huarpe adulto. Febrero 2007)

${ }^{8}$ La asociación entre territorio y parentesco es introducida por Morgan (1877) como criterio para distinguir las formas de gobierno, y retomada con la misma función por Fortes y Evans-Pritchard (1975 [1940]) en el análisis de los sistemas políticos africanos, aludiendo a cómo las relaciones políticas imprimen determinadas significaciones a las relaciones territoriales, y cómo éstas son expresión y reflejan simultáneamente determinadas relaciones políticas. 


\section{Bibliografía}

Alliés, Paul (1980), L’invention du territoire. Presses Universitaires de Grenoble, Grenoble.

Anton Burgos, Francisco Javier (1999), “Nomadismo ganadero y trashumancia: balance de una cultura basada en su compatibilidad con el medio ambiente". En: Anales de Geografía de la Universidad Complutense, $\mathrm{N}^{\mathrm{o}}$ 20, pp. 23-31. ISSN: 0211-9803.

Balibar, Étienne (2005 [1997]), Violencias, Identidades y Civilidad. Para una cultura política global. Gedisa: Barcelona.

Barabas, Alicia (2003), Diálogos con el territorio (coord.).Tomos I a IV. Colección “Etnografía de los pueblos indígenas de México”. INAH, México.

Caillé Alain (2010 [2009]), Teoría anti-utilitarista de la acción. Fragmentos de una sociología general. Waldhuter, Buenos Aires.

Connerton, 1993 [1989]), Como as sociedades recordam. Traducción de Rocha M. Manuela. Celta, Oeiras.

Cragnolini, Mónica (2001), “Para una melancología de la alteridad: diseminaciones derridianas en el pensamiento nietzscheano. En: Revista de la sociedad española de estudios sobre Nietzsche.

Derrida Jacques (2001[1978]), La verdad en pintura. Paidós, Buenos Aires.

Ídem (1996), Le monolinguisme de l'autre. Manantial, Buenos Aires.

Espósito, Roberto (2006 [1999]), Categorías de lo impolítico. Katz, Buenos Aires.

Fortes, Meyer \& Evans-Pritchard, Edvard (1975 [1940]), “Introduction”. En: African political systems. Oxford Univ. Press, London.

Foucault, Michel 2002 [1982]), La hermenéutica del sujeto. Buenos Aires, FCE.

Ídem (2001), “El sujeto y el poder” en Hubert L. Dreyfus \& Paul Rabinow (comp.) Michel Foucault: más allá del estructuralismo y la hermenéutica, Ediciones Nueva Visión, Buenos Aires.

Ídem (1998[1979]), Microfísica do poder. GRAAL, Rio de Janeiro.

Hall, Stuart (2003 [1996]), “¿Quién necesita ‘identidad’? En: S. Hall y Paul del Gay, Cuestiones de identidad. Amorrortu, pp. 13-39, Buenos Aires. 
Halbwachs (2004 [1968] ), La Memoria colectiva. Prensas Universitarias de Zaragoza. Trad. Por Inés Sancho-Arroyo.

Jelin (2002), Los trabajos de la memoria. Siglo XXI, Madrid.

Katzer, Leticia (2012), “Razón gubernamental, biopolítica y mecanismos de capitalización de la praxis indígena en Mendoza”. Revista Espacios Nueva Serie N ${ }^{\circ}$ 7. pp. 173-189. Universidad Nacional de la Patagonia Austral. ISSN 1669-8517.

Ídem (2010), "Reconfiguraciones organizacionales, procesos políticos y territorialización: Los Huarpes como ‘comunidades indígenas' ”. Anales de Arqueología y Etnología No 65 . Facultad de Filosofía y Letras. Universidad nacional de Cuyo. ISSN 0325-0288. En prensa.

Idem (2009), “Tierras indígenas, demarcaciones territoriales y gubernamentalización. El caso Huarpe, Pcia de Mendoza”. Revista Avá nº 16. Universidad Nacional de Misiones, pp. 117-136. ISSN 1851-1694.

Nora (1984), Les Lieux de Mémoire. Gallimard, Paris.

Pacheco de Oliveira (1999)

Poulantzas, Nicole (1978), L'Etat, le Pouvoir et le Socialisme. PUF, Vendome.

Ricoeur, Paul ([2000] 2008), La memoria, la historia, el olvido. FCE, Buenos Aires.

Tamagno, Liliana (2001), Los Tobas en la casa del hombre blanco. Al margen, La Plata.

Woortmann, Klaas (1995), Heredeiros, parentes e compadres. Colonos do Sul e Sitiantes do Nordeste. Hucitec-Edunh, Sao Paulo.

Recibido: 18.02.2013

Aceptado: 07.03.2013 